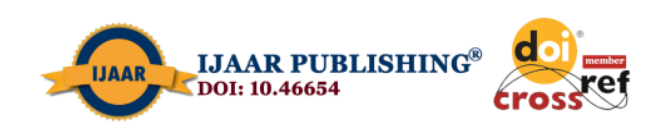

International Journal of Advanced Academic Research (Business and Economic Development) | ISSN: 2488-9849

Journal DOI: 10.46654/ij.24889849

Vol. 6, Issue 11 (November, 2020) |www.ijaar.org

Article DOI: 10.46654/ij.24889849.b6114

\title{
CRISIS MANAGEMENT AND ORGANIZATIONAL RESILIENCE IN TELECOMMUNICATIONS FIRMS IN RIVERS STATE
}

\author{
Isirimah Nnamdi N. \\ University of Port Harcourt Business School, Port Harcourt, Rivers State, Nigeria. \\ B. Chima Onuoha \\ Department of Management, University of Port Harcourt Choba, Rivers State, Nigeria.
}

\begin{abstract}
The research assesses the effect of the crisis management approach and its effect on the corporate resilience of telecommunications companies. The concern with the analysis is that telecommunications companies are under internal and external pressure, which may lead to a true crisis concerning corporate resilience and the resulting loss of productivity and lower earnings. To achieve the objective of the analysis, the self-governing questionnaire was used to collect data. It has been produced and circulated to a survey of 84 respondents. The study states that the different facets of crisis management, such as; Changing Path Strategy, Reserve Mobilization Strategy, Group work Strategy, Crisis Fragmentation Strategy, and Crisis Containment Strategy have potent influence overall on the resilience of telecommunication firms. In the light of this, the study advises that; Businesses should have a center for the training of company leaders and managers and equip them with the requisite capacity to cope with crises. There should be greater interest in the conduct of studies and scientific study and advanced field studies in the area of crisis management, and in collaboration with major organizations and organisations with considerable expertise in this field, businesses should develop effective policies and techniques that lead to crisis management.
\end{abstract}

Keywords: Crisis Management, Organizational Resilience, Crisis Path Strategy. 


\section{INTRODUCTION}

There is no question that we live in a wide world marked by rapid change, and that we face numerous challenges and changes, all of which are major crises at the level of people, communities, organisations and governments (Mikkelsen \& Clegg, 2018). As an entity existing in today's culture, it will at one time or another experience uncertainty in which the effect of the event(s) undermines its service, existence or prestige (Alemu, 2018). The willingness of such an organization to effectively implement plans to handle such a situation is what separates an organization that is capable of handling uncertainty from another organization that causes such a terrible condition to limit its strategic goals (Olang, 2017). Crisis management is thus seen as the provision of an organization's pre-planned, quick response capability, enabled by an integrated leadership, knowledge management and communication capability that facilitates rapid decisionmaking at a strategic level within a formal environment, allowing successful recovery and maintaining the existence or integrity of an organization. In addition, management must ensure that incidents do not occur or that the effect of sensitive circumstances is reduced (Awan \& Saeed, 2015). The crisis is indeed a crucial situation that can have significant negative effects for the company (Yamamoto, Wekeroğlu, \& Bayramoğlu, 2011).

In order to be able to solve these crises, we need structured and consistent methods to help us handle these crises and cope with them in a scientific manner, based on the expertise, experience and skills inherent in a successful management style, through crisis management plans and strategies that are rationally and critically designed to ensure effective outcomes for individuals or organisations (Aytaç \& Basol, 2018).Crisis management reports have also been listings of rhetorical ideas that ignore both the analytical context and the quantitative basis for how organisations should minimize the effects if the crisis is not overcome. There is also a lack of research from an open system perspective on how facets of organizational architecture and the job setting communicate and impact organizational success in sensitive circumstances (Alemu, 2018). Studies have also ranged from constructing statistical frameworks for guiding business organisations and government parastatals on behavior in internal management and military conflict situations (Aytaç \& Basol, 2018), as well as designing educational tools for managing disaster prevention (Bernstein, 2012), and focusing on tactical analysis to improve logistic structures. Although these findings have offered new insights into numerous crisis management problems, they have primarily been focused on institutional analysis and game theory methods, rather than on organizational ideas and techniques that, we think, may offer a far more applicable and better basis for crisis management. An effort is made in this analysis to discuss the fundamental question of how organisations should sustain successful results in the face of critical circumstances from an open system viewpoint for organisations (Thompson, 2007). The management of the crisis of an organisation goes beyond the formulation of a crisis management plan, which has to do with the formulation of a successful strategy through information, coordination, peaceful dialogue, and a different approach to the resolution of the internal crisis of order to maximize overall results (Chaudhry \& Asif, 2015).

Rivers State, by its distinct geographical position in the heart of Nigeria, is vulnerable to foreign or internal crises, whether political or economic. Its public and private institutions are not far from emergencies, threats and challenges in the era of intelligence collisions and are keeping track with increasing global developments. It is also important to look at new and advanced 
solutions to address these crises and the challenges that emerge from them, in a correct analytical way and in a systematic manner, including comprehension, interpretation and time-planning based on crisis management strategies. The goal of this analysis is to define the effect of these crisis management techniques on the organizational resilience of telecommunications companies in Rivers State, Nigeria.

\section{Problem Statement}

The problem of the study is summarized in the researcher's anticipation that telecommunications companies will be exposed to external and internal pressures that could lead to a real crisis affecting their performance and resilience, usually manifesting in the form of paralyzed production and lower profits, and generally affecting their ability to control (Chigozie, 2017). This makes the company look for alternatives and strategies to manage this crisis in a way that will positively reflect on employee performance to boost productivity and maximize profits. Thus, the aim of the study is to identify the impact of crisis management strategies on the organizational resilience of telecommunications companies.

The main question therefore illustrates the problem of the study: What are the most important crisis management strategies (Changing Path Strategy, Crisis Fragmentation Strategy, Group Work Strategy, Crisis Containment Strategy, Reserve Mobilization Strategy, Crisis Exhausting Strategy) that affect the organizational resilience of Telecommunications firms (increasing productivity and maximizing profit).

This study aims at identifying the impact of the strategies of crisis management on the organizational resilience of Telecommunication firms. This objective is divided into the following sub-objectives:

- To identify the impact of Changing Path Strategy on the organizational resilience of Telecommunication firms.

- To examine the impact of Reserve Mobilization Strategy on the organizational resilience of Telecommunication firms.

- To evaluate the impact of Group work Strategy on the organizational resilience of Telecommunication firms.

- To assess the impact of Crisis Fragmentation Strategy on the organizational resilience of Telecommunication firms.

- To investigate the impact of Crisis Containment Strategy on the organizational resilience of Telecommunication firms.

- To identify the impact of Crisis Exhausting Strategy on the organizational resilience of Telecommunication firms.

This study derives its relevance from the fact that the effect of the crisis management approach on the corporate stability of telecommunications companies is an important and critical issue. The relevance of this thesis is demonstrated by the fact that it is considered one of the few studies (according to researchers) specializing in the thesis of crisis management techniques in a business that is one of the largest businesses in the Arab world. The significance of this analysis is to recognize the likelihood of issues or crisis events that may influence the management operation of the organization and the extent of harm arising from the loss of interest or decision- 
making that may contribute to a decline in productivity or a decline in income and impact employees and dealers in generation

These businesses are perceived to be the key backers of the Nigerian economy and its contribution to local and national growth at the level of manufacturing, export and employment. The realistic significance of this report is demonstrated in the presentation of suggestions arising from the study to decision-makers working in telecommunications firms as well as other related companies, and in the recognition of the effects of the adoption of crisis management techniques by the organization on its staff in order to ensure the continuity of the work of the company. The analysis is further outlined in the following pages;

\section{LITEERATURE REVIEW}

\subsection{Theoretical Framework}

There are different views on conflict. Conflict can be seen as positive and necessary on the one hand, since when handled in the right manner, it can encourage creative thinking, it also makes an analysis of the necessity of certain thoughts and actions. Nonetheless, mainstream views of confrontation are distinct and are notable. Therefore, the report describes the diverse opinions on organizational rivalry as follows.

\subsubsection{Traditional Theories/Views of Organizational conflict:}

This school of thought, first established in the late 1930s and early 1940s and credited to Rahim (1986), says that confrontation must be stopped as it represents malefaction within the community. Conflict is poorly perceived and is related to conflict and devastation (Nnam, 2018). Conflict is a result of inadequate coordination between individuals and a loss of faith. Only at a high level of administration will disputes be removed or settled. That is the philosophy with the most linear and straightforward approach to dispute. All disputes should be avoided, according to this opinion. Therefore, in order to enhance community and organizational efficiency, it is important to pay attention to and correct the causes of conflict (Chung, 2015). Many disagreements have negative connotations, evoke negative emotions and sometimes contribute to devastation. The methods used to deal with it rely on whether the result of confrontation is positive or bad (Rahim, 1986). This organizational dispute has historically been perceived quite negatively. This was known as unstable. It still has a detrimental effect on the efficacy of an organisation. This confrontation is treated as aggression, devastation and unfounded by a conventional approach. According to this approach, with a strong organizational structure, disputes may be avoided, which in turn offers thorough elaboration and specification of jurisdiction, duty, transparency, policies, procedures and laws. They conclude that all conflicts are terrible and that these conflicts can be prevented to the extent practicable (Nnam, 2018). For a long time, the conventional understanding of war fell out of favour as philosophers and scholars understood that a war was inescapable under certain situations.

\subsubsection{The Human Relations or Contemporary View:}

From the late 1940 s to the mid-70s, the idea gained popularity. This theory / view sees rivalry in all classes as a natural phenomenon. The school for human relations embraces confrontation. 
This implies that disagreement can support the success of a group (Robbins, 2005). From time to time, confrontation exists and it is not prudent to invest too much work into avoiding or preventing conflict. Concentrating only on significant or vital disputes helps individuals to help and more efficiently address the dispute (Leung, 2010). Conflict is seen as a natural and necessary result of individuals working together in groups and teams, according to this view. Therefore, it does not inherently need to be regarded negatively, but rather positively as a possible factor to add to individual success (Abiodun, 2014).

\subsection{Conceptual Framework}

\subsubsection{Crisis and Crisis Management:}

Charles McClelland (1972) describes crisis as a particular mode of expression in the context of the relationship between the parties to the conflict and this change is related to the nature of the reciprocal actions between them because, owing to the use of force or threat, the crisis escalates on the actions of armament, but in the case of reduced intensity of the crisis, the rate of armistice acts starts to decline. According to Bieber, the crisis is a turning point in dysfunctional circumstances which, if the parties involved are unwilling or unable to control or reduce their risks, will lead to undesirable outcomes. In short, the crisis indicates a danger to the interests, principles, beliefs and property of people, organisations and states that restrict the decisionmaking process, as well as a predictable or unpredictable danger. The ongoing management mechanism that deals with the forecasting of future crises through the identification and tracking of internal or external environmental developments that cause crises and the deployment of the tools available to avert or plan to deal with crises in the most successful and productive way to do the least possible risk to the organisation (Dominic, 2012).

\subsection{Empirical Framework}

Few studies have been undertaken in light of conflict management, some are summarized as follows;

Kharadz (2018) analyzed the effect of the practice of crisis-facing transition strategies on corporate success in the Nigerian banking sector. The survey analysis consisted of (209) persons employed in four banks: Arab Bank, Bank of Jordan and Bank Society-General, Housing Bank for Trade and Finance, and was chosen using the system of stratified random sampling. To test the research variables that had the required validity and reliability, a questionnaire was created. To answer the research questions and to test the theories, suitable statistical techniques were also used. The study concluded that the most important findings are: the degree of practice of reform strategies in the face of crises was high in the Nigerian banking sector, where the degree of practice of empirical logical and normative reduction strategies was also high, whereas the degree of practice of the power repressive strategy was medium. In the Nigerian banking sector, the level of corporate success was high. The study proposed a variety of suggestions in the light of these results; the most important one is to enhance the practice of scientific rational and normative reduction strategies and to aim to merge them in the Nigerian banking sector; and to prevent the use of power repressive technique.

Olawale (2014) explored the effect of crisis management approach on the corporate success of multinational organizations in Nigeria, Promassidor Ltd's analytical perspective. Crisis 
management forms the foundation of healthy coexistence between employers and workers and also society as a whole. In every organisation, crisis is unavoidable because it comes in different forms and degrees.

Mohammad (2011) used a documentary descriptive methodology focused on similar previous articles and books to describe crisis management techniques from an Islamic point of view. The researcher discussed the current idea of crisis, its characteristics, phases and consequences. The analysis concluded that coping with crises involves bypassing the conventional methods of response in order to pursue more creative approaches.

Bernstein (2012) focused on crisis management strategies and their implementation to the controversy of the American professional golfer Tiger Woods. Following the scandal, a case study review of Woods' official press releases was carried out to determine what strategies and methods his crisis management team employed and how effective they were in repairing the reputation of Woods.

Leung (2009) analyzed the degree to which industrial organizations are equipped to handle the crises and to assess the impact of the following factors on the preparation of cry management: knowledge \& connectivity, clarification of duties and obligations, incentives, departmental cooperation, and available resources. The study results revealed that industrial organizations are vulnerable.

Alkshali and Al-Qutob (2007) investigated the level of MIS efficacy in Nigerian industrial corporations' crisis management. The analysis was based on a null hypothesis saying "there is no statistically meaningful impact on Crisis Management Knowledge Systems at alpha 0.05 since it followed the descriptive empirical methodology. The findings revealed that the various elements of MIS efficacy as a whole had a meaningful impact on the capacity of administrators to handle the crises they faced."

Yamamoto and Şekeroğlu (2011) analyzed the Turkish leather industry's patterns in crisis management with a questionnaire analysis to classify business executives' ideas about the crisis. The analysis was based on a null hypothesis that "there is no statistically relevant effect on the increase of Turkish leather performance at alpha 0.05 in crisis management" The study concluded that most businesses in the Turkish leather industry do not have a widely accepted internal policy to be applied in crisis management emergencies, are ignorant of tested approaches and means, and do not think much about concerns such as making a team of staff ready to respond quickly against an unexpected situation and taking tentative measurements.

Mahdieh (2015) analyzed General Motors (GM) 's option of crisis negotiation approach through the company's filing for Chapter 11. The research uses the model of Coombs situational crisis communication theory (SCCT) as a basis to explain and propose future selections of crisis communication strategy. The analysis showed that in successfully negotiating reputational management during a financial crisis, GM adopted the principles outlined by the SCCT model. The study indicates that organizations facing comparable crises should adopt a similar set of tactics, but leadership transitions should be taken into consideration in the set of Contract Cluster strategy. 


\section{METHODOLOGY}

The cross sectional approach was used to identify the impact of the crisis management strategy on organizational resilience of the Telecommunication firms, as well as the statistical treatment of the variables of the study and its correlations according to the questions and the hypotheses of the study and the results of the study and its recommendations. The target population are employees of various telecommunication firms in Rivers State. The author employed the convenience sampling technique and employed a sample size of 84 using the stratified and simple random sampling techniques to select the respondents from various alternating telecommunication firms whereby the employees were stratified according to their designation. Questionnaires were used to collect data which were validated through a pilot study. The questions were closed ended on a five point Likert scale. Descriptive statistics and Regression analysis was used to analyze data.

\section{RESULTS AND DISCUSSIONS}

The study proceeds to summarize the results of the study as follows;

\section{Hypotheses Testing:}

First sub-hypothesis (H01): there is no significant implication of Changing Path Strategy in improving the organizational resilience of Telecommunication firms.

\section{Table 1: Changing Path Strategy and Organizational Resilience}

\begin{tabular}{|l|l|l|l|l|l|}
\hline Calculated F & Beta & Sig. & R & $\mathrm{R}^{2}$ & Decision \\
\hline 291.214 & 0.844 & $* 0.001$ & 0.222 & 0.049 & Reject \\
\hline
\end{tabular}

The results seen in table 1 suggest that the significance level (0.002) is lower than $(0.05)$, so the judgment rule states that the alternative hypothesis should be adopted if the significance level (Sig.) is lower than (0.05) and the null hypothesis should be dismissed if the significance level (Sig.) is lower than (0.05). From the previous map, it is clear that Sig. It is less than 0.05, but the judgment rule says that the Evolving Route Approach has a statistically important effect on improving the corporate resilience of telecommunication companies.

Second sub-hypothesis (H02): The reserve deployment approach has no major effect on enhancing the corporate resilience of telecommunications companies.

\section{Table 2: Reserve Mobilization Strategy and Organizational Resilience}

\begin{tabular}{|l|l|l|l|l|l|}
\hline Calculated F & Beta & Sig. & $R$ & $R^{2}$ & Decision \\
\hline 150.027 & 0.641 & $* 0.002$ & 0.641 & 0.411 & Reject \\
\hline
\end{tabular}


The results seen in Table 2 suggest that the meaning level $(0.002)$ is lower than $(0.05)$, so the judgment rule states that the alternative hypothesis should be adopted if the meaning level (Sig.) is lower than (0.05) and that the null hypothesis should be dismissed if the significance level (Sig.) is lower than (0.05). From the previous map, it is clear that Sig. It is less than 0.05, but the judgment rule says that the reserve mobilization approach has a statistically important effect on enhancing the operational resilience of telecommunication companies.

Third sub-hypothesis (H03): the community job approach had no major impact on enhancing the corporate resilience of telecommunications companies.

\section{Table 3: Group work Strategy and Organizational Resilience}

\begin{tabular}{|l|l|l|l|l|l|}
\hline Calculated F & Beta & Sig. & $R$ & $R^{2}$ & Decision \\
\hline 140.896 & 0.680 & $* 0.004$ & 0.518 & 0.268 & Reject \\
\hline
\end{tabular}

The results displayed in Table 3 suggest that the meaning level (0.002) is lower than (0.05), so the judgment rule states that the alternative hypothesis should be adopted if the meaning level (Sig.) is lower than (0.05) and that the null hypothesis should be dismissed if the significance level (Sig.) is lower than (0.05). From the previous map, it is clear that Sig. The decision rule says that the Community Job Approach has a statistically important effect on increasing the corporate resilience of telecommunications organizations. It is less than 0.05 .

Fourth sub-hypothesis (H04): The crisis fragmentation approach has no major impact on strengthening the corporate resilience of telecommunications companies.

Table 4: Crisis Fragmentation Strategy and Organizational Resilience

\begin{tabular}{|l|l|l|l|l|l|}
\hline Calculated F & Beta & Sig. & $\mathrm{R}$ & $\mathrm{R}^{2}$ & Decision \\
\hline 144.637 & 0.541 & $* 0.000$ & 0.673 & 0.452 & Reject \\
\hline
\end{tabular}

The results seen in table 4 suggest that the significance level (0.002) is lower than (0.05), so the judgment rule states that the alternative hypothesis should be adopted if the significance level (Sig.) is lower than (0.05) and the null hypothesis should be dismissed if the significance level (Sig.) is lower than (0.05). From the previous map, it is clear that Sig. It is less than 0.05, but the judgment rule says that the Crisis Fragmentation Approach has a statistically important effect on improving the operational resilience of telecommunication companies.

Fifth sub-hypothesis (H05): The crisis containment approach had no major effect on enhancing the corporate stability of telecommunications companies. 
Journal DOI: 10.46654/ij.24889849

Table 5: Crisis Containment Strategy and Organizational Resilience

\begin{tabular}{|l|l|l|l|l|l|}
\hline Calculated F & Beta & Sig. & R & $R^{2}$ & Decision \\
\hline 144.417 & 0.673 & $* 0.020$ & 0.673 & 0.452 & Reject \\
\hline
\end{tabular}

The results seen in table 5 show that the significance level (0.002) is lower than $(0.05)$, so the judgment rule states that the alternative hypothesis should be adopted if the significance level (Sig.) is lower than (0.05) and the null hypothesis should be dismissed if the significance level (Sig.) is lower than (0.05). From the previous map, it is clear that Sig. It is less than 0.05, but the judgment rule says that the Crisis Containment Approach has a statistically important effect on improving the operational stability of telecommunication companies.

Sixth sub-hypothesis (H06): The Crisis Exhausting Approach has little major effect on enhancing the corporate stability of telecommunications companies.

\section{Table 6: Crisis Exhausting Strategy and Organizational Resilience}

\begin{tabular}{|l|l|l|l|l|l|}
\hline Calculated F & Beta & Sig. & R & $R^{2}$ & Decision \\
\hline 144.514 & 0.651 & $* 0.000$ & 0.222 & 0.049 & Reject \\
\hline
\end{tabular}

The findings shown in table 6 show that the meaning level (0.002) is lower than (0.05), so the judgment rule states that the alternative hypothesis must be accepted if the meaning level (Sig.) is lower than (0.05) and that the null hypothesis must be dismissed if the meaning level (Sig.) is lower than (0.05). From the previous map, it is clear that Sig. The decision rule says that the Crisis Exhausted Approach has a statistically important effect on improving the corporate stability of telecommunication companies.

\section{CONCLUSION AND RECOMMENDATIONS.}

In conclusion, the paper states that crisis management is a clear formula for the stability of organisations. With the introduction of a 24 hour news cycle and an increasingly internet-savvy audience with ever evolving technologies at its fingertips, the need for management is even more critical. It is the unique duty of elected officials to help shield us from the harmful impacts of emergencies. Crisis management specialists remember that they concern themselves with all stages of the crisis; the period of incubation, the beginning, and the aftermath. Five essential activities are then used in crisis leadership: sense making, decision making, and purpose making, terminating and understanding. In conclusion, every company organization's longevity and success relies on its employees because a large proportion of an organization's value is decided not just by the organization's recruiting and training practices, but also by the manner in which the organization's structure and culture facilitates strategic production of human capital. Although this mission is very difficult to fulfill, a first and important step towards a remarkable accomplishment in this sector starts with a clear understanding of what workers need in terms of 
career growth. This helps the organisation to adapt its capacities and skills and channel all of its available capital in their different ways to fulfill these needs.

The researchers propose the following on the basis of the findings obtained by this study:

i. Companies should provide a hub for the training of business executives and managers and equip them with the skills required to cope with emergencies.

ii. The interest in conducting studies and experimental research, and advanced field studies in the field of crisis management, should be enhanced.

iii. In collaboration with large organizations and entities who have significant expertise in this area, companies can develop effective policies and strategies that lead to crisis management.

iv. Keep workshops and educational programmes for executive branch administrators, administrators and heads.

v. Dependence on strategic planning should be in order to deter business disasters.

vi. Combine government and private strategies to identify effective ways to alleviate the crises that Nigerian enterprises are facing. 


\section{References}

Abiodun, A. R. (2014). Organizational conflicts: Causes, effects and remedies. International Journal of Academic Research in Economics and Management Sciences, 3(6), 118.

Alemu, L. (2018). Organizational conflict management strategies of hotel sectors in ethiopia: employees perception on the practices in case of selected hotels in Wolaita Sodo Town, Southern Ethiopia. The International Journal Of Business \& Management, 10-16.

Alkshali, S. J., \& Al-Qutob, M. (2007). Effectiveness of management information systems and their impact on crisis management: field study on Jordanian industrial companies. Jordan Journal of Business Administration, 3(1), 24-45.

Awan, A. G., \& Saeed, S. (2015). Conflict management and organizational performance: a case study of Askari Bank Ltd. Research Journal of Finance and Accounting, 6(11), 88-102.

Aytaç, S., \& Basol, O. (2018). Mediating role of loneliness and organizational conflict between work overload and turnover intention. In Congress of the International Ergonomics Association (pp. 291-301). Springer, Cham.

Bernstein, M. (2012). "Thou Shall not Protest": Multi-Institutional Politics, Strategic Nonconfrontation and Islamic Mobilizations in Turkey. In Nonviolent Conflict and Civil Resistance. Emerald Group Publishing Limited.

Chaudhry, A. M., \& Asif, R. (2015). Organizational Conflict and Conflict Management: a synthesis of literature. Journal of Business and Management Research, 9, 238-244.

Chigozie, N. E. (2017). Impact of organizational conflict on employee job performance in selected hotels (in Lagos Nigeria). Turizam, 21(1), 45-64.

Chung, Y. W. (2015). The mediating effects of organizational conflict on the relationships between workplace ostracism with in-role behavior and organizational citizenship behavior. International Journal of Conflict Management.

Do, H. R. (2017). The effects of technostress and nomophobia on burnout, organizational conflict and job performance: A case of travel agent employee (Doctoral dissertation, Doctoral dissertation, KyonggiUniveristy, Suwon).

Dominic, B. (2012). Walking toward conflict. Tikkun, 27(1), 21-70.

Ebhote, O., \&Osemeke, M. (2015). Conflict Management: Managerial Approach towards Improving Organizational Performance. International Review of Social Sciences and Humanities, 9(1), 51-60.

Fiaz, M., Ikram, A., Su, Q., \& Ali, N. (2018). How to save the saviors?: Relationship between organizational justice and citizenship behavior. The Journal of Developing Areas, 52(1), 45-58. 
Hasani, K., Boroujerdi, S. S., Sheikhesmaeili, S., \& Aeini, T. (2018). Identity of organizational conflict framework: Evaluating model factors based on demographic characteristics in Iran. Journal of Industrial Engineering and Management (JIEM), 7(5), 1013-1036.

Henry, O. (2017). Organizational Conflict and its effects on Organizational Performance. Research journal of business management, 2(1), 16-24.

Hossain, Z. (2017). The Impact of Organizational Conflict on Employees' Performance in Private Commercial Banks of Bangladesh. IOSR Journal of Business and Management (IOSR-JBM), 19(10), 12-21.

Jokanović, B., Tomić, I., \& Duđak, L. (2017). Organizational conflict resolution. In Proceedings of the XVII International Scientific Conference on Industrial Systems, IS (pp. 446-451).

Jordan, P. J., \& Troth, A. C. (2002). Emotional intelligence and conflict resolution in nursing. Contemporary Nurse, 13(1), 94-100.

Kharadz, N. (2018). Organizational conflict management challenges. European Journal of Economics and Business Studies, 10(1), 30-41.

Leung, Y. F. (2009). Conflict management and educational intelligence. Unpublished Thesis for Degree of Business Administration, Southern Cross University, Lismor.

Longe, O. (2015). Impact of workplace conflict management on organizational performance: A case of Nigerian manufacturing firm. Journal of Management and Strategy, 6(2), 83-92.

Mahdieh, O. (2015). Interaction between communication and organizational conflict and its relationship with performance. Interaction, 1(2), 6-12.

McClelland, D. C. (1972). The drinking man: Alcohol and human motivation.

Mikkelsen, E. N., \& Clegg, S. (2018). Unpacking the meaning of conflict in organizational conflict research. Negotiation and Conflict Management Research, 11(3), 185-203.

Mohammad, Y. (2011). A proposed dynamic model for conflict management. African Journal of Business Management, 5(16), 6727-6737.

Nnam, M. U. (2018). Conflict and conflict management: A springboard for success and progress in organisations in Nigeria. International Journal of Development and Management Review, 8(1), 54-66.

Olang, B. A. (2017). The influence of conflict management on organizational performance: a case of stimasacco society limited (Doctoral dissertation, United States International University-Africa).

Olawale, S. R. (2014). Crisis management strategy and its effects on organizational performance of multinational corporations in Nigeria: Empirical Evidence from Promassidor Ltd. European Journal of Business and Management. 6(23), 79-87. 
Rahim, M. A. (1986). Referent role and styles of handling interpersonal conflict. The Journal of social psychology, 126(1), 79-86.

Robbins, S. (2005). Organizational Behavior: New Jersey: Prentice Hall.

Thompson, E. O. P., \& O'donnell, I. J. (1960). The chromatography of insulin on DEAEcellulose in buffers containing 8M urea. Australian Journal of Biological Sciences, 13(3), 393-400.

Yamamoto, G. T., Şekeroğlu, Ö., \& Bayramoğlu, E. E. (2011). Marketing activities in the leather industry: comparative country analysis. International Journal of Economics and Management Sciences, 1(3), 37-48. 